\title{
Beyond the Pummerer Reaction: Recent Developments in Thionium Ion Chemistry
}

\author{
Laura H. S. Smith, Susannah C. Coote, Helen F. Sneddon, and David J. Procter*
}

cyclization · heterocycles - Pummerer reaction - sulfur .

thionium ions

Since the early 1960s the Pummerer reaction has evolved to become an indispensable tool for synthesis, and continues to serve as a source of inspiration for organic chemists. In recent years, many exciting advances have demonstrated the broad scope and synthetic utility of Pummerer methodology and the versatility of thionium ion intermediates.

\section{Introduction}

The substrate of the classical Pummerer reaction ${ }^{[1]}$ is an alkyl sulfoxide $\mathbf{1}$ which, upon $\mathrm{O}$ activation, undergoes elimination to give a thionium ion $\mathbf{2}$, which is attacked by a nucleophile. In general, the sulfoxide is activated using acetic anhydride, trifluoroacetic anhydride (TFAA), trifluoromethanesulfonic anhydride $\left(\mathrm{Tf}_{2} \mathrm{O}\right)$, or a silyl chloride. Common examples of nucleophiles include acetate, arenes, alkenes, amides, and phenols as these are usually sufficiently unreactive towards the electrophile used to activate the sulfoxide. Direct sulfide activation with oxidants such as $\mathrm{N}$ chlorosuccinimide (NCS) or Stang's reagent (PhI(CN)OTf) is also possible. The use of aromatic or vinyl sulfoxides allows additive and vinylogous reactions to be added to the family of Pummerer processes, and some activated sulfoxides are attacked by a nucleophile at sulfur, giving rise to interrupted Pummerer reactions (Scheme 1).

Here we survey recent advances in Pummerer and thionium ion chemistry reported since the excellent reviews of Padwa ${ }^{[2]}$ Feldman ${ }^{[3]}$ and Kita. ${ }^{[4]}$ Recent applications in natural product synthesis, nucleoside synthesis, and fluorous methods pay further testament to the versatility of the Pummerer reaction.

[*] L. H. S. Smith, Dr. S. C. Coote, Prof. D. J. Procter School of Chemistry, University of Manchester Oxford Road, Manchester M13 9PL (UK) Fax: (+44) 161-275-4939

E-mail: david.j.procter@manchester.ac.uk Homepage: http://people.man.ac.uk/ mbdssdp2/

Dr. H. F. Sneddon

Medicines Research Centre, GlaxoSmithKline Gunnels Wood Road, Stevenage, Herts, SG1 2NY (UK)

$$
\text { Additive }
$$

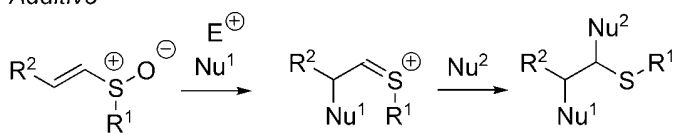

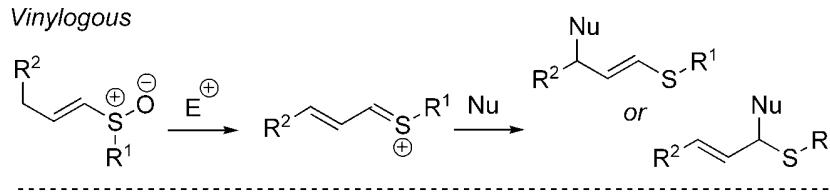

Interrupted

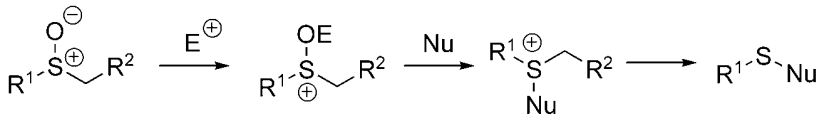

Scheme 1. The "classical" Pummerer reaction and the additive, vinylogous, and interrupted variants.

\section{General Applications of the Pummerer Reaction \\ 2.1. Pummerer Fragmentation Reactions}

Lacour and co-workers have reported a novel Pummerer fragmentation reaction in which a thionium ion is generated by cleavage of the $\mathrm{C}_{\alpha}-\mathrm{C}_{\beta}$ bond in an activated sulfoxide, where $\mathrm{X}$ is an electron-rich triarylmethine group (Scheme 2). ${ }^{[5]}$ Mechanistic studies have been performed to ascertain the scope of the reaction. ${ }^{[6]}$ Sulfoxides $r a c-3 \mathbf{A}(1.5: 1$ d.r.) and $\mathbf{3 B}$ gave $\mathbf{4}$ and deeply colored salts $\mathbf{5 A}$ and $\mathbf{5 B}$, respectively, in near-quantitative yield on exposure to TFAA (Scheme 3). Sulfoxide 3D gave only the Pummerer rear- 


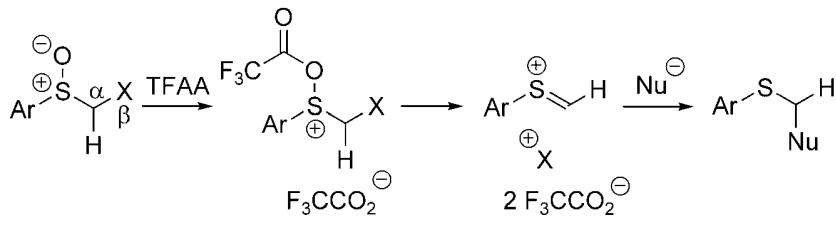

Scheme 2. Pummerer fragmentation.

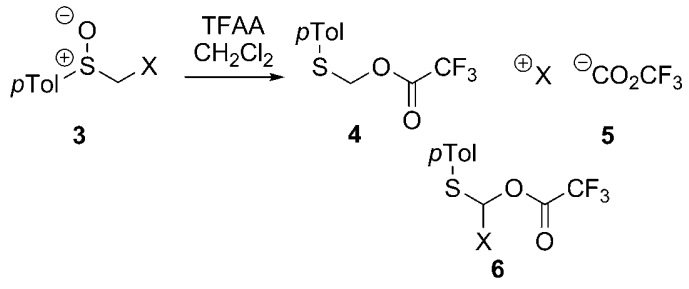
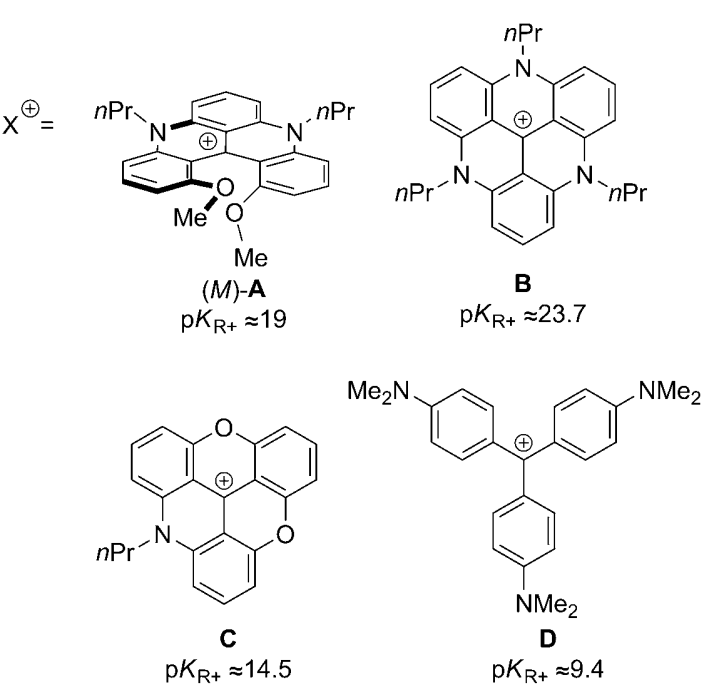

Scheme 3. Pummerer fragmentation substrates and products. $p \mathrm{Tol}=$ para-tolyl.

rangement product 6D (59\% yield of isolated product), with no salt 5D detected by NMR spectroscopy. Finally, on activation, 3C gave a mixture including salt 5C (48\%) and the Pummerer rearrangement product $6 \mathbf{C}$, which could not be isolated, indicating that both fragmentation and rearrangement mechanisms were in operation. These results suggest that a $\mathrm{p} K_{\mathrm{R}+}$ value greater than 14.5 is necessary for fragmentation to occur. This reaction has been used to resolve chiral cationic dyes: treatment of rac-A with $(R)$ methyl- $p$-tolylsulfoxide and lithium diisopropylamide (LDA) gave two separable diastereoisomeric sulfoxides, which fragmented on treatment with $\mathrm{HPF}_{6}$ in acetone to give both enantiomers of $\mathbf{A}$ as $\mathrm{PF}_{6}{ }^{-}$salts in greater than $98 \%$ ee ${ }^{[5]}$

\subsection{Vinylogous Pummerer Reactions}

Feldman and co-workers have developed new methodology for the construction of spirocyclic oxindoles using the Pummerer reaction of indole-2-sulfoxides or -sulfides bearing a pendant carboxylate group or activated alkene functionality (allylsilanes, silyl enol ethers, or silyl ketene iminals). ${ }^{[7]}$ Indole-2-sulfides 7a, 8a, and 9a were activated with Stang's reagent, whereas indole-2-sulfoxides $\mathbf{7 b}, \mathbf{8 b}$, and $\mathbf{9 b}$ were activated with $\mathrm{Tf}_{2} \mathrm{O}$ in the presence of 2,6-lutidine (Scheme 4). Spirocyclic oxindole derivatives were generally obtained in good yield, and complete regioselectivity for cyclization at $\mathrm{C} 3$ on the indole was observed.

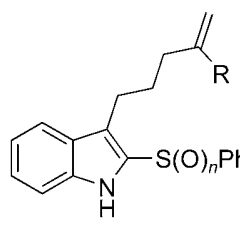

$7 \mathbf{a}, \mathbf{b} \mathrm{R}=\mathrm{OSiPr}_{3}$ $\mathbf{8 a}, \mathbf{b} \mathrm{R}=\mathrm{CH}_{2} \mathrm{SiMe}_{3}$ (a: $n=0 ; \mathbf{b}: n=1$ )

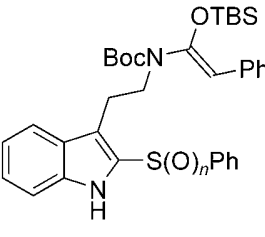

9a $n=0$

$9 \mathbf{b} n=1$
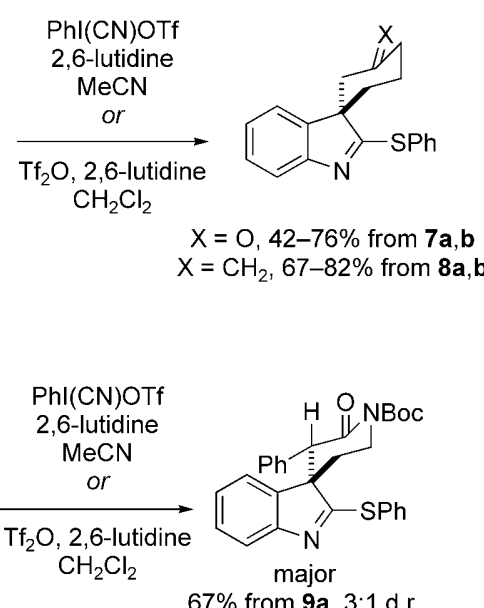

$67 \%$ from $9 a, 3: 1$ d.r. $82 \%$ from $9 b, 6.8: 1$ d.r.
Scheme 4. Formation of spiroindoles using an extended Pummerer reaction. Boc $=$ tert-butoxycarbonyl, TBS $=$ tert-butyldimethylsilyl.

Interestingly, under Pummerer conditions, enol ether $\mathbf{1 0}$ did not give the expected product of $\mathrm{C}-\mathrm{C}$ bond formation; instead cyclization occurred through the nitrogen atom of the

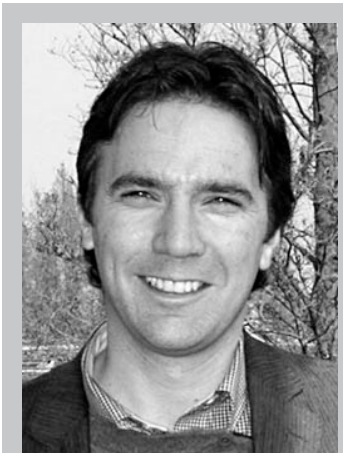

David Procter completed a PhD at the University of Leeds with Prof. Chris Rayner in 1995. After postdoctoral work with Prof. Robert Holton at Florida State University in Tallahassee, he took up a Lectureship at the University of Glasgow in 1997. In September 2004 he moved to Manchester and was promoted to Professor in October 2008. His interests lie in organosulfur chemistry, the development of new organic reactions using $\mathrm{Sml}_{2}$, and natural product synthesis.

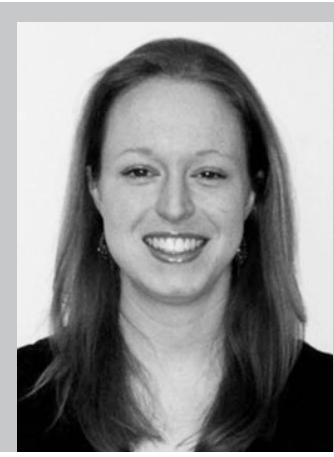

Susannah Coote studied chemistry at the University of York and the Universite Joseph Fourier (France). She obtained her PhD in 2007 from the University of York, working under the supervision of Prof. Peter O'Brien. In 2009, after a postdoctoral stay in the group of Prof. Cyrille Kouklovsky at the Université Paris-Sud 11 (France), she joined the group of David Procter in Manchester as a postdoctoral research associate to work on strategies for fluorous synthesis. 
bicyclic system to ultimately generate spiroazetidine $\mathbf{1 1}$ (Scheme 5). ${ }^{[8]}$

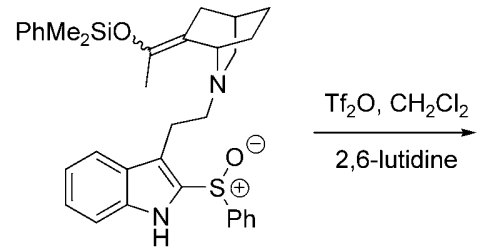

10

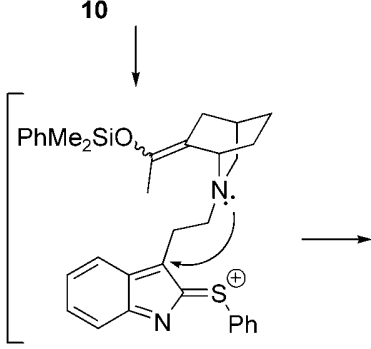

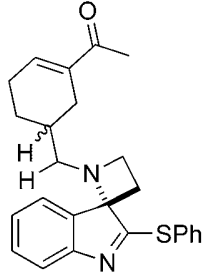

11

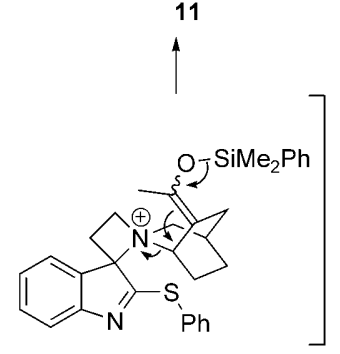

Scheme 5. Pummerer cyclization to form a spiroazetidine.

Yorimitsu and Oshima have shown that arylketene dithioacetal monoxides $\mathbf{1 2}$ undergo an extended, intermolecular Pummerer reaction when activated by $\mathrm{Tf}_{2} \mathrm{O}$ in the presence of an aromatic nucleophile. ${ }^{[9]}$ The reaction is thought to occur via a dicationic intermediate 13; a solvent screen showed the most polar of those investigated, nitromethane, to be optimal, and cation stabilization effects could account for this observation (Scheme 6).

The electron-withdrawing trifluoromethyl group of 2-(2,2,2-trifluoroethylidene)-1,3-dithiane monoxide $\mathbf{1 4}$ is thought to destabilize the postulated dicationic intermediate analogous to $\mathbf{1 3}$. The regiochemistry of product formation when $\mathrm{R}^{1} \neq \mathrm{H}$ supports the proposition that under Pummerer conditions, $\mathbf{1 4}$ reacts with an allylsilane nucleophile by attack at sulfur (an interrupted Pummerer reaction) followed by a $[3,3]$-sigmatropic rearrangement (Scheme 7). ${ }^{[10]}$

Extended thionium ions are also involved in the cyclization of ketene dithioacetals $\mathbf{1 5}$ to form substituted unsaturated $\delta$-lactones $\mathbf{1 7}$, reported by Wang, Liu, et al. ${ }^{[1]}$ The reaction is believed to proceed via thionium ion 16, which then undergoes an extended Pummerer reaction. Attempted lactonization of carbocyclic analogue $\mathbf{1 8}$ gave only the

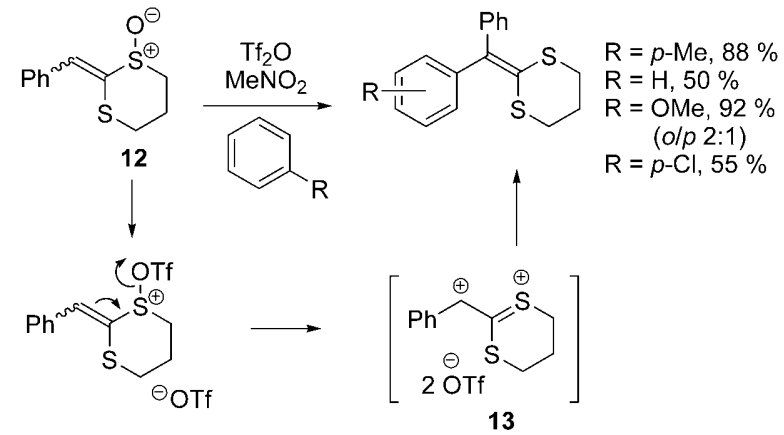

Scheme 6. Pummerer-type reaction of ketene dithioacetal derivatives.<smiles>[O-][Sb]1CCCSC1=CC(F)(F)F</smiles><smiles>[R1]C=C([R])C[R16](C)(C)C</smiles>

$$
\begin{aligned}
& \mathrm{R}^{1}=\mathrm{R}^{2}=\mathrm{H}, 86 \% \\
& \mathrm{R}^{1}=\mathrm{H}, \mathrm{R}^{2}=\mathrm{Me}, 86 \% \\
& \mathrm{R}^{1}=\mathrm{H}, \mathrm{R}^{2}=\mathrm{Ph}, 87 \% \\
& \mathrm{R}^{1}=\left(\mathrm{CH}_{2}\right)_{2} \mathrm{Ph}, \mathrm{R}^{2}=\mathrm{H}, 74 \% \\
& (E / \mathrm{Z} 99: 1)
\end{aligned}
$$

Scheme 7. Reaction of ketene dithioacetal derivatives with allylsilanes. $\mathrm{TMS}=$ trimethylsilyl.
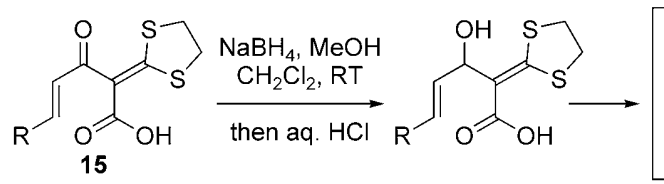<smiles>[R]C=CC=C(C(=O)O)C1=[S]CCS1</smiles><smiles>O=C(O)C(C(=O)/C=C/c1ccccc1)=C1CCCC1</smiles>
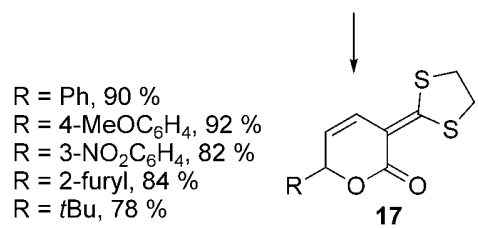

Scheme 8. Lactonization of ketoacids via a thionium ion intermediate.

corresponding hydroxy acid, thus illustrating the importance of thionium ions in the process (Scheme 8 ).

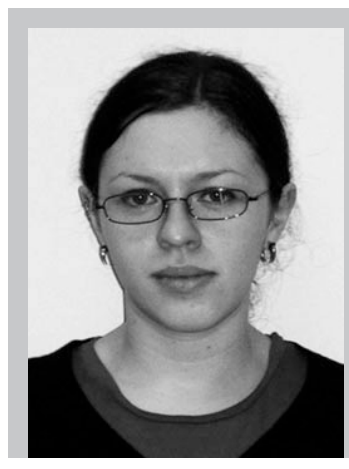

Laura Smith graduated from the University of Leeds in 2008. She is currently conducting PhD research under the supervision of David Procter at Manchester. Her work involves the use of connective Pummerertype reactions in the synthesis of antitumor natural products.

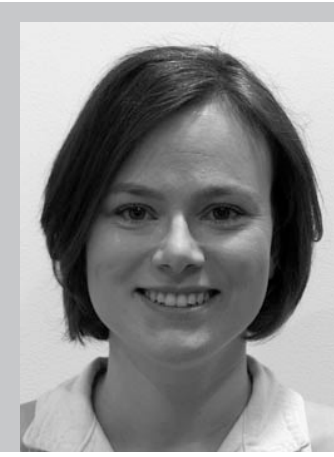

Helen Sneddon studied natural sciences at the University of Cambridge, and completed a PhD in organic chemistry with Prof. Steven Ley in 2005. After postdoctoral work with Prof. Larry Overman at the University of California, Irvine, she joined GlaxoSmith Kline in 2007 as a medicinal chemist. 


\subsection{Pummerer Reactions To Make Heteroaromatic Rings}

Satoh and Miyagawa have developed a two-step procedure for the synthesis of 2-aryl-5-(phenylsulfanyl)furans from alkenylaryl ketones that involves a Pummerer cyclization. ${ }^{[12]}$ Thus, conjugate addition of the lithium carbanion derived from dichloromethylphenyl sulfoxide to $\mathbf{1 9}$ gave intermediate $\mathbf{2 0}$ in high yield (Scheme 9). ${ }^{[12]}$ Compound $\mathbf{2 0}$ was then treated

$$
\text { (O) }
$$

Scheme 9. Furan synthesis using a Pummerer cyclization. HMPA $=$ hexamethylphosphoramide.

with TFAA and $\mathrm{NaI}$ to give the corresponding furan 22 in good yield. The reaction is thought to proceed by a Pummerer-type mechanism involving thionium ion 21. To introduce further functionalization, the phenylsulfanyl group in furan $\mathbf{2 2}$ was oxidized to the corresponding sulfoxide using meta-chloroperbenzoic acid ( $m \mathrm{CPBA})$, followed by sulfoxide-metal exchange using $i \operatorname{PrMgCl}$. Subsequent quenching of the resulting 2-magnesiofuran with a range of electrophiles including benzoyl chloride allowed access to substituted 2-arylfurans such as $\mathbf{2 3}$ (Scheme 9).

Zhou et al. have exploited a Pummerer-type process for the synthesis of 5-vinyl-1,3-oxazoles such as $\mathbf{2 7}$ and 28. ${ }^{[13]}$ For example, treatment of propargyl sulfoxides such as $\mathbf{2 4}$ and $\mathbf{2 5}$ with TFAA gave conjugated thionium ions $\mathbf{2 6}$, which were captured by an internal amide nucleophile (Scheme 10).

\subsection{Interrupted Pummerer Reactions}

Yuste, García Ruano, and co-workers have utilized the nonoxidative Pummerer reaction developed by the Zanda group $^{[14]}$ to remove a sulfoxide stereocontrol element that had previously been used to control the stereochemical course of a ketone reduction, in an approach to $\alpha$-hydroxy- $\beta$-amino acids. ${ }^{[15]}$ For example, treatment of sulfoxides 29 and $\mathbf{3 0}$ with TFAA and sym-collidine gave alcohols $\mathbf{3 1}$ and $\mathbf{3 2}$ in good yield after in situ hydrolysis of the intermediate trifluoroacetates (Scheme 11). The reaction is thought to involve salts $\mathbf{3 3}$

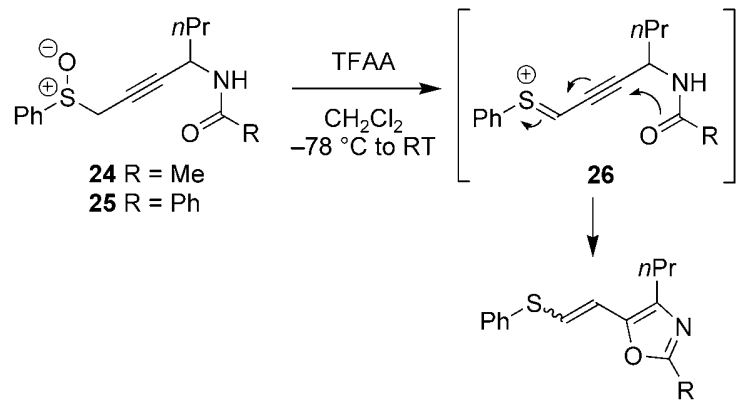

$27 \mathrm{R}=\mathrm{Me}, 82 \%, E / Z 2: 1$

$28 \mathrm{R}=\mathrm{Ph}, 70 \%, E / Z 1: 1$

Scheme 10. Synthesis of oxazoles using a long-range Pummerer reaction.

$$
\text { sym-collidine }
$$

Scheme 11. Removal of a sulfoxide stereocontrol element using a Pummerer reaction.

and/or sulfuranes $\mathbf{3 4}$, although neither was observed when the reactions were monitored by NMR spectroscopy. Attempts to intercept salts $\mathbf{3 3}$ with alternative nucleophiles were also unsuccessful, perhaps suggesting an intramolecular process during which trifluoroacetate is transferred and the $\mathrm{C}-\mathrm{S}$ bond is broken (Scheme 11).

Bates and co-workers reported the conversion of 2-indoleanilides 35 into indolo[3,2-b]-1,5-benzothiazepinones 36 using an interrupted Pummerer reaction (Scheme 12). ${ }^{[16]}$

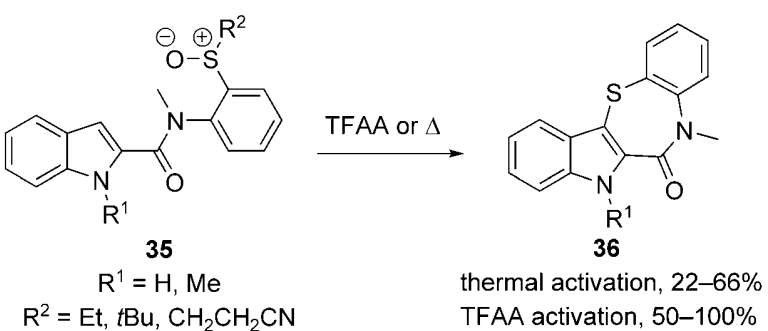

Scheme 12. Interrupted Pummerer reaction to form benzothiazapinones. 
The reactions were carried out either under thermal activation (heating in chloroform or xylene) or electrophilic activation (treatment with TFAA). Successful reaction requires the absence of an amidic hydrogen; the presence of an amidic hydrogen is assumed to result in formation of an $\mathrm{N}-\mathrm{H} \cdots \mathrm{O}-\mathrm{S}$ hydrogen bond that stabilizes the trans-amide conformation, in which the sulfur atom cannot interact with the indole $\pi$ electrons (Scheme 12).

\section{Pummerer Reaction in the Synthesis of Thio- and Selenonucleosides}

Since the pioneering work of the O'Neil ${ }^{[17]}$ and Yoshimura groups ${ }^{[18]}$ the Pummerer reaction has been used extensively in the synthesis of thionucleosides. Haraguchi et al. have recently exploited an additive Pummerer reaction in conjunction with a more conventional Pummerer process to prepare thioribofuranoses and thio- $C$-nucleosides. ${ }^{[19]}$ Treatment of vinylsulfoxide 37 with $\mathrm{Ac}_{2} \mathrm{O}$ and $\mathrm{BF}_{3} \cdot \mathrm{OEt}_{2}$ in the presence of TMSOAc gave diacetate glycosyl donor $\mathbf{3 8}$ in $61 \%$ yield (Scheme 13). The inclusion of TMSOAc was necessary to limit opening of the silylene protecting group. Donor 38 was subsequently exploited as a precursor to thionium ion 39, which underwent nucleophilic addition from
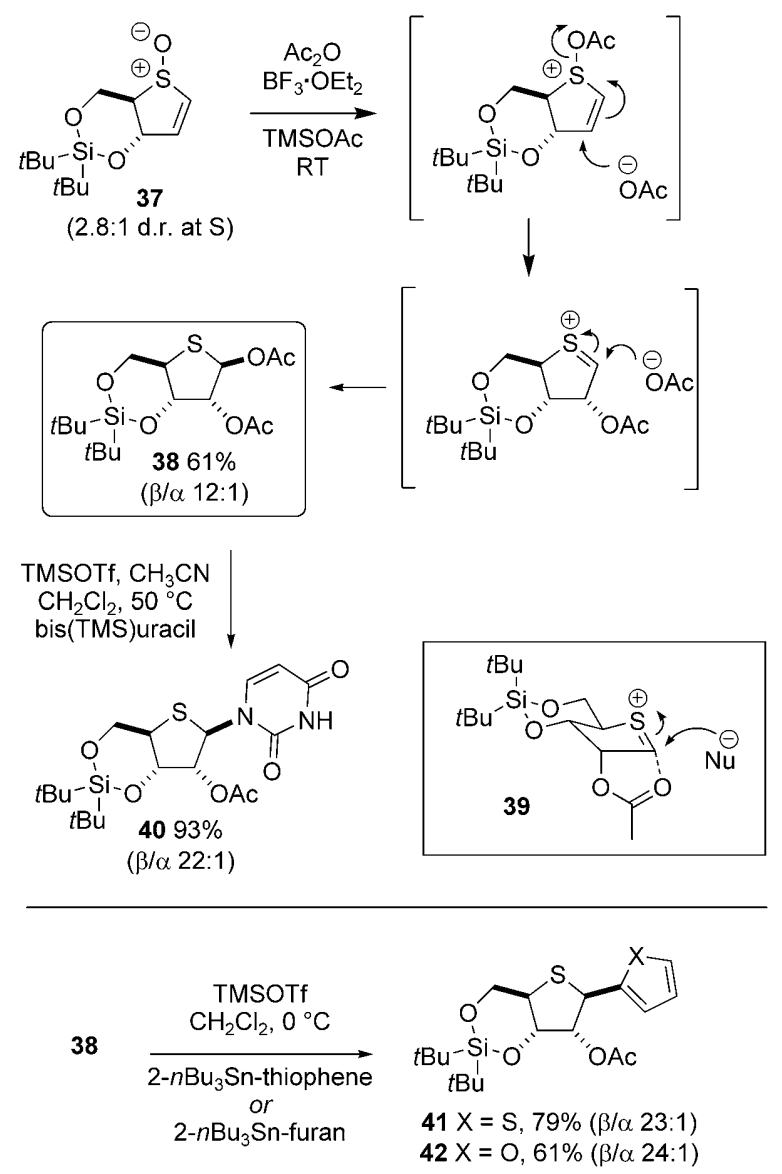

Scheme 13. Synthesis of thionucleosides and their analogues using an additive Pummerer reaction. the $\beta$ face to give adducts $\mathbf{4 0 ,} \mathbf{4 1}$, and $\mathbf{4 2}$ in moderate to good yield (Scheme 13).

Yoshimura, Takahata, et al. have utilized a Pummerer thioglycosylation process in a synthesis of thiopyranonucleoside 43. ${ }^{[20,21]}$ The study sheds valuable light on the regiochemistry of addition to conjugated thionium ion intermediates $\mathbf{4 9}$. Whereas sulfoxide $\mathbf{4 4}$ underwent Pummerer reaction to give the $\alpha$ adduct $\mathbf{4 6}$ selectively, sulfoxide $\mathbf{4 5}$ gave a small amount of $\gamma$ adduct 48 (Scheme 14). Re-exposing the $\alpha$ adduct $\mathbf{4 7}$ to

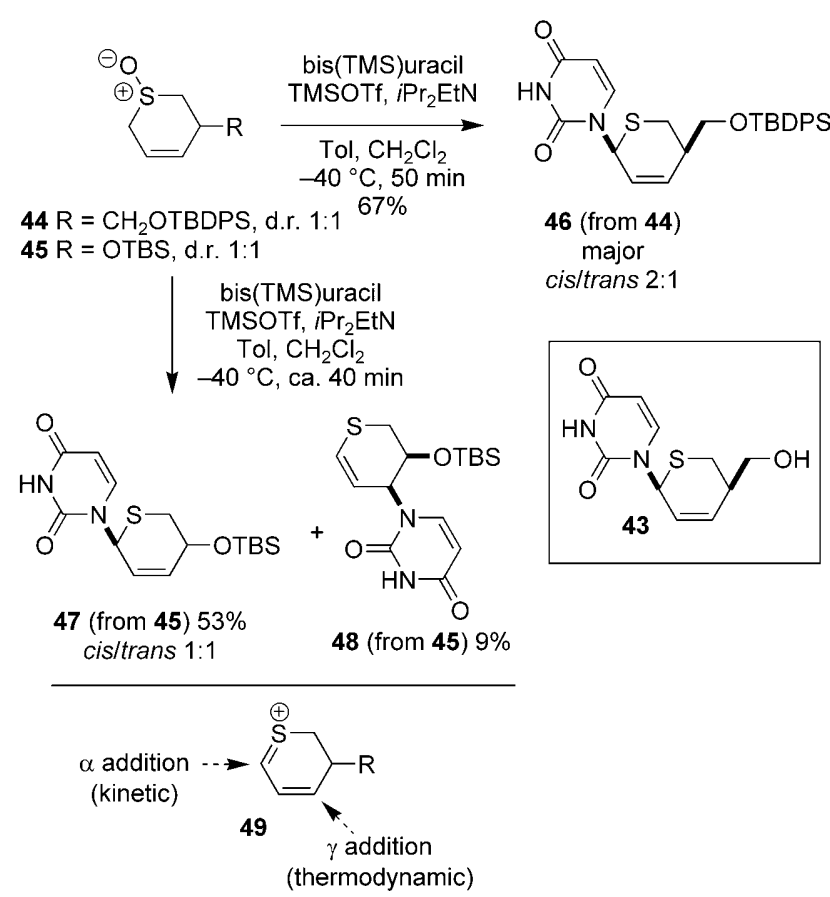

Scheme 14. Thiopyranonucleosides formed using a vinylogous Pummerer reaction. TBDPS $=$ tert-butyldiphenylsilyl, Tol $=$ toluene.

the Pummerer conditions resulted in smooth conversion to $\gamma$ adduct $48(67 \%)$, suggesting that the $\alpha$ adducts are formed under kinetic control whereas $\gamma$ adducts are the thermodynamic products. Sulfoxides that are diastereoisomeric at sulfur reacted at different rates but gave similar reaction outcomes, suggesting that a common conjugated thionium ion was formed from either sulfoxide diastereoisomer. It is therefore clear that the regiochemistry of addition to conjugated thionium ions can depend on the substituents on the thionium ion and on the reaction temperature and duration (Scheme 14). Gulea and co-workers have also studied the regiochemistry of addition to $\beta, \gamma$-unsaturated thionium ions derived from (2-methylsulfanyl-2-phosphanyl) thiopyran-1-oxides, and using a trifluoroacetate nucleophile, observed reaction at the $\gamma$ position only. ${ }^{[22]}$

The stereochemistry at sulfur in sulfoxide substrates for Pummerer thioglycosylation can, however, be critical. Bhat et al. found that only the $R$ sulfoxide $\mathbf{5 1}$ underwent smooth thioglycosylation, while the analogous $S$ sulfoxide underwent side reactions under Pummerer conditions. $R$ Sulfoxide $\mathbf{5 1}$ was therefore prepared selectively from sulfide $\mathbf{5 0}$ by asymmetric oxidation (Scheme 15). ${ }^{[23]}$ 

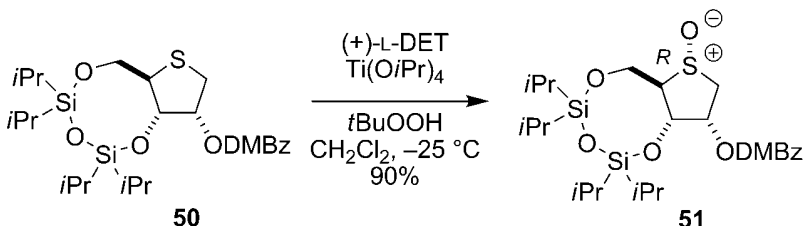

50

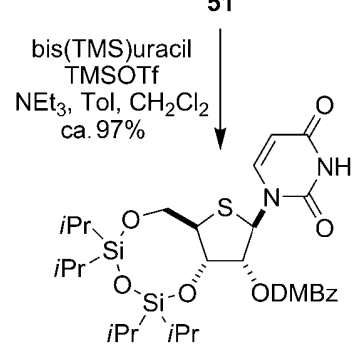

Scheme 15. Stereoselective oxidation and Pummerer reaction of the resulting sulfoxide. $\mathrm{DMBz}=2,4$-dimethoxylbenzoyl, $\mathrm{DET}=$ diethyl tartrate.

The configuration at sulfur in sulfoxide substrate $\mathbf{5 2}$ was also crucial in Paquette and Dong's approach to thiaspirocyclic ribonucleosides. ${ }^{[24]}$ Pummerer glycosylation of sulfoxide $\mathbf{5 2}$ gave unwanted vinyl sulfoxide $\mathbf{5 4}$ as the major product although the desired $\beta$ adduct $\mathbf{5 3}$ was isolated in $35 \%$ yield. The analogous sulfoxide, diastereoisomeric at sulfur, gave only the vinyl sulfoxide analogous to $\mathbf{5 4}$ with no trace of Pummerer adducts (Scheme 16).

Chu and co-workers have utilized the Pummerer thioglycosylation of thietane sulfoxides in a synthesis of several thietanose nucleosides. ${ }^{[25]}$ Finally, Pinto et al. have used an analogous Pummerer glycosylation of selenoxide $\mathbf{5 5}$ in the synthesis of several selenonucleosides (Scheme 17). ${ }^{[26]}$

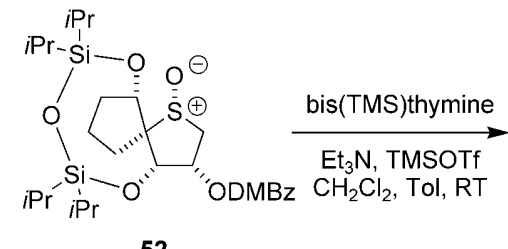

52

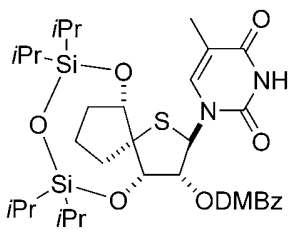

$5335 \%$

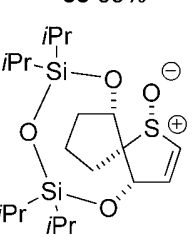

$5465 \%$

Scheme 16. Synthesis of thiaspirocyclic nucleosides.

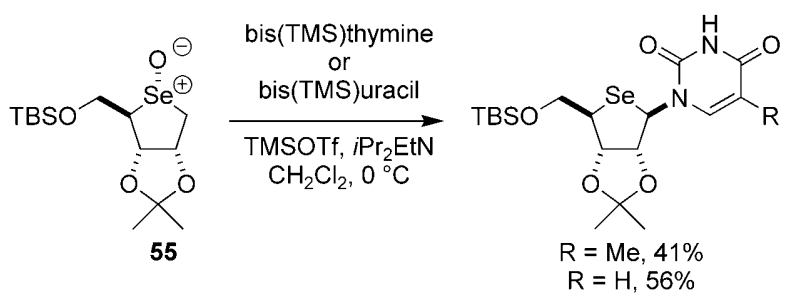

Scheme 17. Synthesis of selenonucleosides using a Pummerer reaction.

\section{Pummerer Reactions Using an Alternative Method of Thionium Ion Formation}

\subsection{The Connective Pummerer Reaction}

The Procter group has utilized a connective approach to thionium ions from aldehyde and thiol starting materials that involves the in situ formation and activation of hemithioacetal intermediates 56 (Scheme 18). ${ }^{[27,28]}$ The connective Pummerer

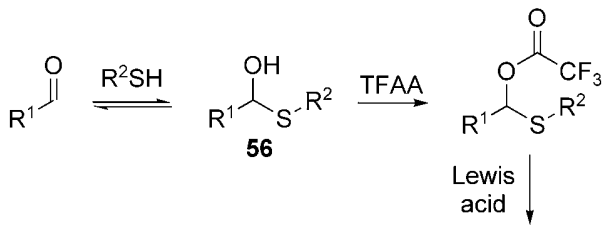

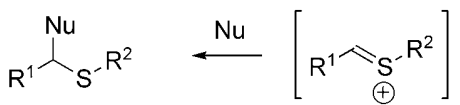

Scheme 18. A connective route to thionium ions.

reaction has a number of attractive features: it uses readily available starting materials, does not require the synthesis of sulfides and sulfoxides, and is useful for convergent synthesis as the structural features of the aldehyde, thiol, and nucleophile are incorporated into the product.

The connective Pummerer reaction has been exploited in a cyclative-capture strategy for the fluorous synthesis of $\mathrm{N}$-heterocycles. Treatment of the readily prepared glyoxamide starting materials $\mathbf{5 7}$ with a fluorous thiol $\left(\mathrm{C}_{8} \mathrm{~F}_{17} \mathrm{CH}_{2} \mathrm{CH}_{2} \mathrm{SH} ; \mathrm{R}^{\mathrm{F} S H}\right)$, then TFAA followed by $\mathrm{BF}_{3} \cdot \mathrm{Et}_{2} \mathrm{O}$ gave the heterocyclic products $\mathbf{5 8}$ in good yield (Scheme 19); oxindoles, tetrahydroisoquinolones, and tetrahydrobenzazepinones may be prepared by straightforward variation of the
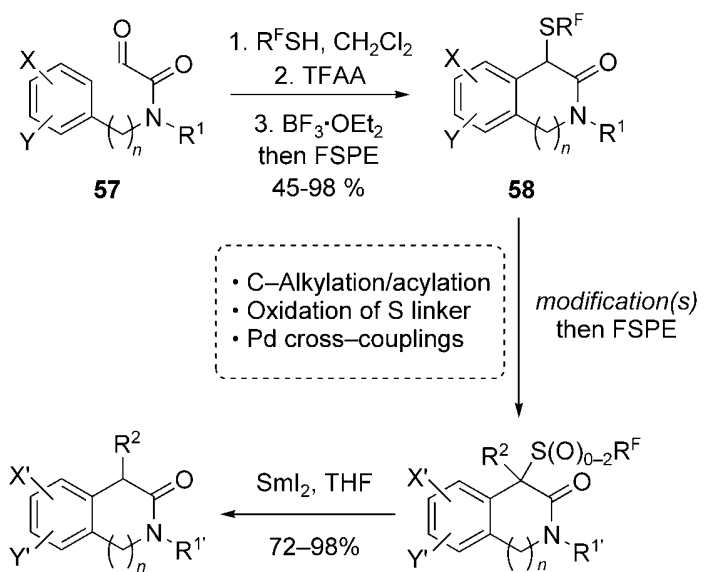

59

$$
n=0,1,2
$$

$\mathrm{X}, \mathrm{Y}=\mathrm{H}, \mathrm{OMe}, \mathrm{F}, \mathrm{Cl}, \mathrm{Br}$

$\mathrm{R}^{1}=$ alkyl, $\mathrm{PSE}, \mathrm{Bn}, \mathrm{PMB}$, allyl

Scheme 19. Cyclative-capture using a connective Pummerer reaction and modification of the resulting heterocycles. $\mathrm{R}^{\mathrm{F}}=\mathrm{CH}_{2} \mathrm{CH}_{2} \mathrm{C}_{8} \mathrm{~F}_{17}$, $\mathrm{FSPE}=$ fluorous solid-phase extraction, $\mathrm{Bn}=$ benzyl, $\mathrm{PMB}=4$-methoxybenzyl, PSE = 2-phenylsulfonylethyl. 
glyoxamide substrate. Thus, a strategic cyclization event is triggered during the introduction of a fluorous tag and the construction of a robust sulfur linker. ${ }^{[29]}$ The use of a fluorous tag allows products to be purified by fluorous solid-phase extraction (FSPE). The tagged heterocycles formed in the Pummerer-type reaction can be modified in a variety of ways. For example, the sulfur atom linkage to the fluorous tag facilitates alkylation/acylation reactions, and oxidation of the linking sulfur atom to the corresponding sulfone allows efficient palladium-catalyzed cross-coupling reactions to be carried out (e.g. Sonogashira/Suzuki cross-couplings, Buchwald-Hartwig aminations). Finally, traceless removal of the fluorous tag to give $N$-heterocycles $\mathbf{5 9}$ was achieved by reduction using samarium(II) iodide (Scheme 19). ${ }^{[27,28]}$

Procter et al. further evaluated the scope of the connective Pummerer process by investigating the reaction of a range of functionalized alkyl and aryl thiols with glyoxamides derived from secondary anilines. ${ }^{[30]}$ The expected oxindole products 60 were obtained in moderate to good yields over two steps; thus the methodology tolerates thiols bearing a range of different functional groups (aryl rings, ester, bromide, amino, and hydroxy groups) (Scheme 20).
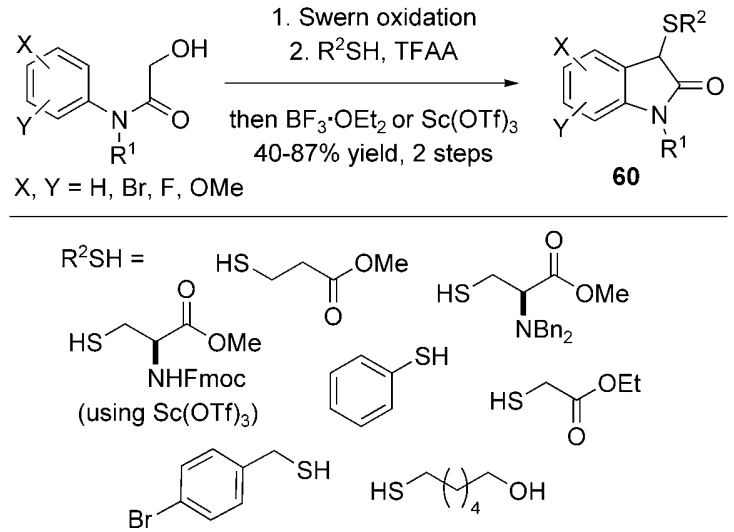

Scheme 20. Exploring the scope of the connective Pummerer reaction. $\mathrm{Fmoc}=$ 9-fluorenylmethoxycarbonyl.

Extension of this work allowed the development of the first two-directional Pummerer cyclizations. Hence, reaction of readily accessible bis-1,3-glyoxamides, such as $\mathbf{6 1}$, with a range of functionalized thiols gave the expected bis-oxindole products, such as $\mathbf{6 2}$, in acceptable overall yields. The reaction of the related bis-1,4-glyoxamides $\mathbf{6 3}$ with thiols gave oxindoles as mixtures of isomers 64 and $\mathbf{6 5}$, with the linear isomers predominating (2:1 to $>5: 1$ regioselectivity) (Scheme 21). ${ }^{[30]}$

The connective Pummerer-type cyclization was applied in the fluorous synthesis of neocryptolepine (66), an indoloquinoline natural product that has shown to be a sequenceselective DNA intercalator, and an analogue 67 (Scheme 22). ${ }^{[31]}$ A tagged oxindole was prepared by Pummerer cyclization and then alkylated using 2-nitrobenzyl bromide, to give oxindoles $\mathbf{6 8}$ after purification by FSPE. Treatment with samarium(II) iodide cleaved the fluorous tag and reduced the nitro group, and subsequent cyclization
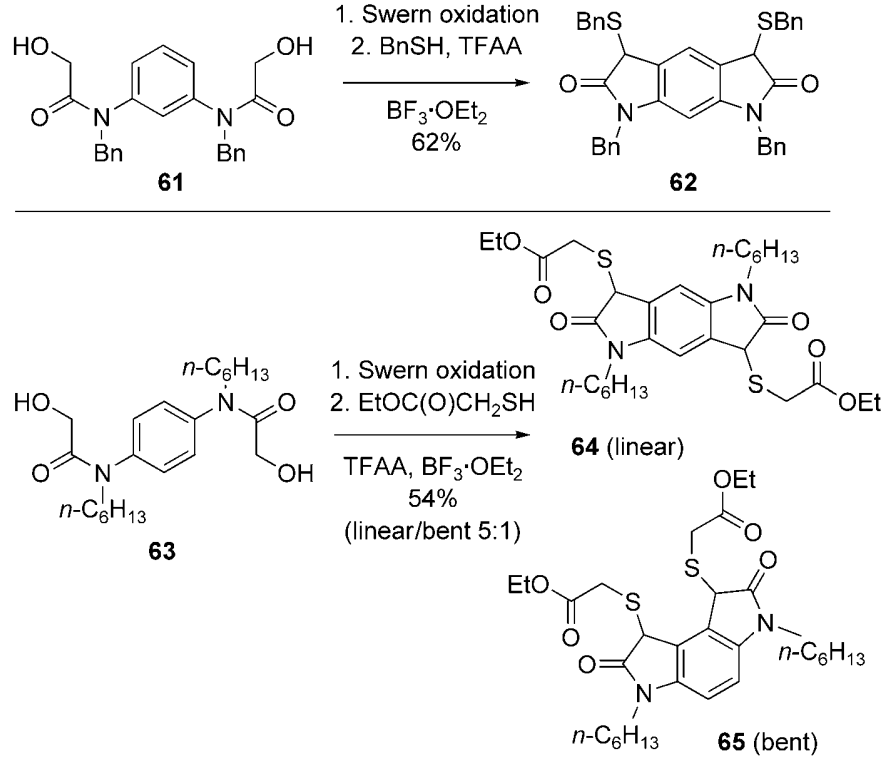

Scheme 21. Two-directional connective Pummerer reactions.
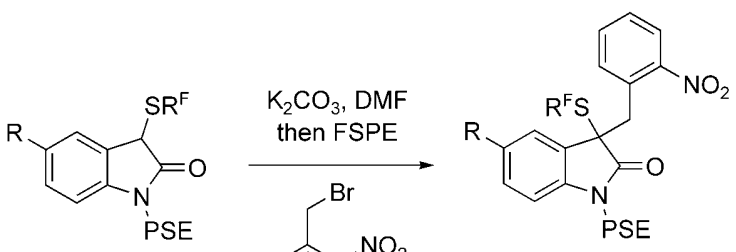

$\mathrm{R}=\mathrm{H}, \mathrm{Me}$

68a $\mathrm{R}=\mathrm{H}, 75 \%$

68b $\mathrm{R}=\mathrm{Me}, 82 \%$
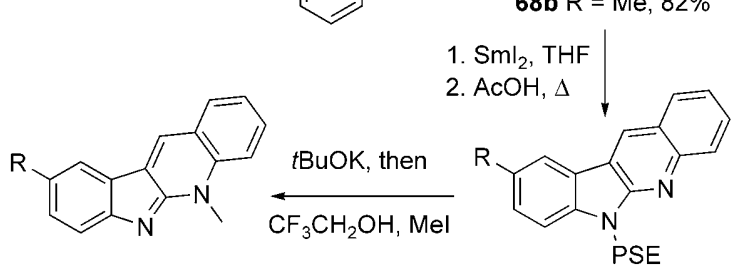

$66 \mathrm{R}=\mathrm{H}, 69 \%$

$67 \mathrm{R}=\mathrm{Me}, 70 \%$

69a $\mathrm{R}=\mathrm{H}, 83 \%$

$69 \mathrm{~b} R=\mathrm{Me}, 60 \%$

Scheme 22. A connective Pummerer-type cyclization in a fluorous synthesis of neocryptolepine (66). $\mathrm{R}^{\mathrm{F}}=\mathrm{CH}_{2} \mathrm{CH}_{2} \mathrm{C}_{8} \mathrm{~F}_{17}$.

under acidic conditions gave 69. Finally, removal of the PSE group and methylation provided neocryptolepine (66) and its analogue 67 (Scheme 22).

The Procter group has also exploited the connective approach to generating thionium ions in dearomatizing cyclizations to form azaspirocyclic cyclohexadienones. ${ }^{[32]}$ For example, treatment of $N$-isopropylglyoxamides 70 a and $70 \mathbf{b}$ with thiophenol and the commercial fluorous thiol $\mathrm{C}_{8} \mathrm{~F}_{17} \mathrm{CH}_{2} \mathrm{CH}_{2} \mathrm{SH}$ gave spirocycles $\mathbf{7 1}$ and 72, respectively, in moderate overall yield (Scheme 23). The spirocyclization of unsymmetrical glyoxamide $\mathbf{7 0} \mathbf{b}$ proceeded with high levels of diastereocontrol to give the anti product $\mathbf{7 2}$ through transition structure 73. The alkyl or arylsulfanyl group introduced during the thionium ion cyclization can act as a synthetic handle, phase tag, and stereochemical control element in subsequent modifications of the azaspirocyclic framework. 

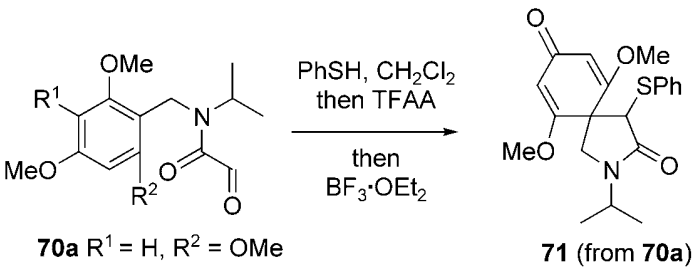

70a $R^{1}=H, R^{2}=$ OMe

$70 \mathrm{~b} \mathrm{R}^{1}=\mathrm{OMe}, \mathrm{R}^{2}=\mathrm{H}$

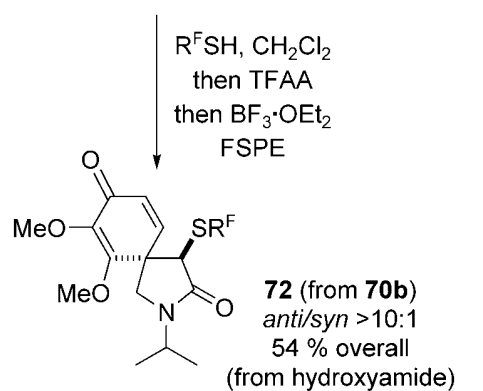

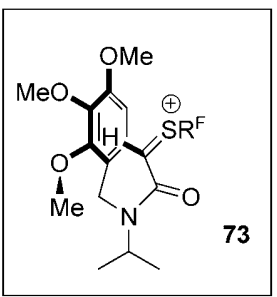

Scheme 23. Formation of azaspirocyclic cyclohexadienones. $\mathrm{R}^{\mathrm{F}}=\mathrm{CH}_{2} \mathrm{CH}_{2} \mathrm{C}_{8} \mathrm{~F}_{17}$

In some cases the spirocyclic cationic intermediates formed upon thionium ion cyclization, such as $\mathbf{7 4}$, collapsed to give products of aryl transfer after hydrolysis of an intermediate $N$-acyliminium ion $\mathbf{7 5}$ (Scheme 24). The process corresponds to an intramolecular arylation of a thionium ion and is a useful alternative to intermolecular variants as it is regiospecific, works well for hindered aryl groups, including di-ortho-substituted aryl groups, and proceeds in good overall yield. Procter et al. have exploited the process in a fluorous synthesis of medicinally important $\alpha$-arylacetamides. ${ }^{[33]}$ The use of a fluorous thiol to trigger aryl transfer allows intermediates in the synthesis to be purified by FSPE. In contrast to traditional fluorous syntheses, the introduction of<smiles>CCOC(=O)CCCC(=O)N(Cc1ccc(Br)cc1OC)C(C)C</smiles>

FSPE

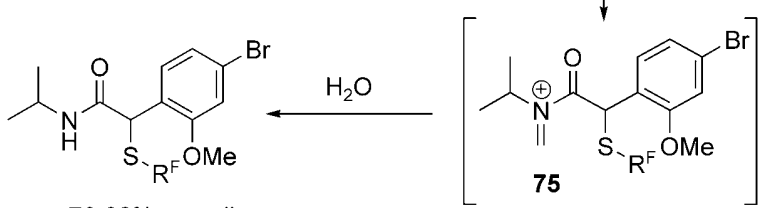

$7666 \%$ overal

(from hydroxyamide)

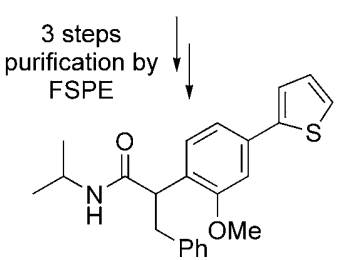

Scheme 24. A connective Pummerer-type reaction in a fluorous synthesis of $\alpha$-arylacetamides. $\mathrm{R}^{\mathrm{F}}=\mathrm{CH}_{2} \mathrm{CH}_{2} \mathrm{C}_{8} \mathrm{~F}_{17}$. the fluorous tag is achieved as part of a key reaction and adds no additional steps to the route.

Mahrwald and Seifert have recently synthesized highly substituted thiochromans such as $\mathbf{7 9}$ from thiophenol and aldehydes or trioxanes. ${ }^{[3]}$ Although the reaction mechanism has not been determined, Mahrwald proposes aldol condensation to give $\mathbf{7 7}$ and the subsequent cyclization of a cationic species, such as thionium ion $\mathbf{7 8}$, to give product $\mathbf{7 9}$ (Scheme 25).

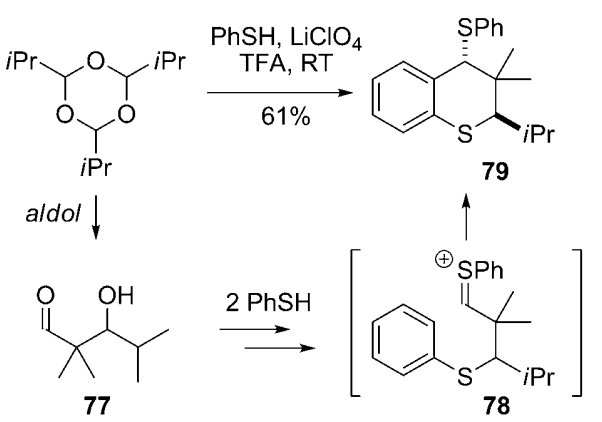

Scheme 25. Synthesis of thiochromans via thionium intermediate 78

\subsection{Pummerer Reactions Initiated by Oxidative Electron Transfer}

In their studies on fluorous synthesis using a sulfur linker, Procter et al. developed an oxidative tag cleavage-modification protocol that is complementary to the samarium(II) iodide reductive cleavage (see Scheme 19, Scheme 22, and Scheme 24) ${ }^{[35]}$ Thus, treatment of tagged oxindoles such as $\mathbf{8 0}$ with ceric(IV) ammonium nitrate (CAN) resulted in a Pummerer reaction to provide isatins such as $\mathbf{8 1}$ in excellent yields. Such compounds are versatile intermediates for the introduction of structural diversity (Scheme 26).

Also driven by a desire to access thionium ions from sulfides without first forming the corresponding sulfoxides, $\mathrm{Li}$
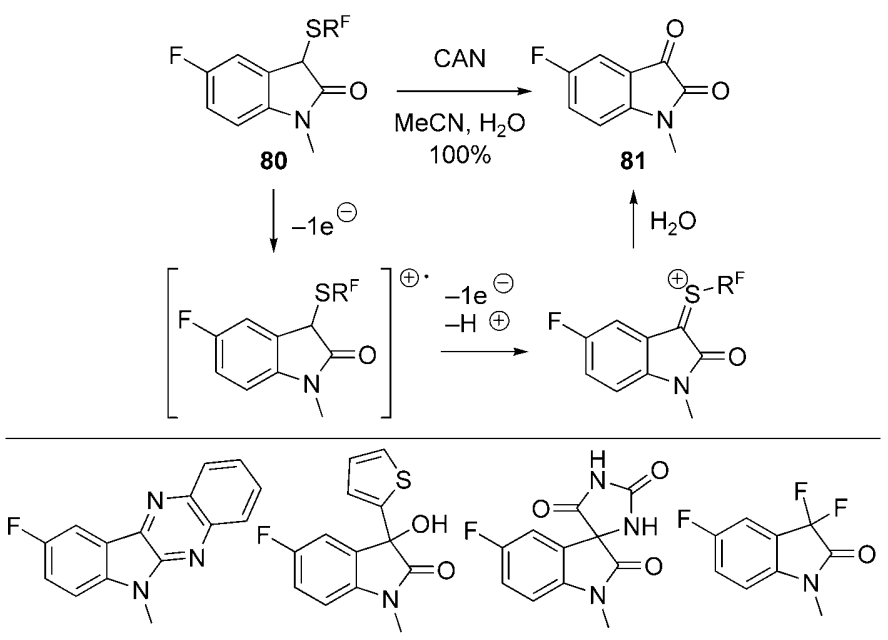

$90 \%$ from 81

$74 \%$ from 81

$56 \%$ from 81

$77 \%$ from 81

Scheme 26. CAN-initiated Pummerer reaction for the removal of a fluorous tag. $\mathrm{CAN}=$ cerium(IV) ammonium nitrate, $\mathrm{R}^{\mathrm{F}}=\mathrm{CH}_{2} \mathrm{CH}_{2} \mathrm{C}_{8} \mathrm{~F}_{17}$. 
and co-workers have reported the direct oxidation of sulfides 82 to thionium ions by electron transfer using the $o$-quinone, $o$-choranil. ${ }^{[36]}$ The resulting thionium ions undergo reactions with a range of 1,3-dicarbonyl compounds to give the expected sulfide products $\mathbf{8 3}$ in good yield (Scheme 27). Use of excess oxidant and elevated temperature $\left(100^{\circ} \mathrm{C}\right)$ resulted in elimination of the organosulfanyl group and direct formation of Knoevenagel products $\mathbf{8 4}$.

$$
\begin{aligned}
& \begin{array}{l}
\text { 82a } \mathrm{R}=\mathrm{Me} \\
82 \mathrm{~b}=\mathrm{Ph} \\
82 \mathrm{c}=\mathrm{Bn}
\end{array} \\
& \begin{array}{c}
\text { O-chloranil } \\
(1.5 \text { equiv) } \\
\text { neat }
\end{array}
\end{aligned}
$$

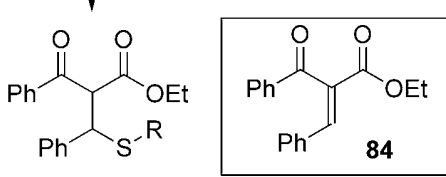

Scheme 27. A Pummerer-type process initiated by oxidative electron transfer.

\section{Asymmetric Pummerer Reactions}

The Feldman group's studies on the synthesis of spirocyclic indoles using the Pummerer reaction (see Section 2.2) were extended to include reactions of enantiopure indole-2sulfoxides $\mathbf{8 5}$ and $\mathbf{8 6}$, which bear a pendant allylsilane and a silyl enol ether functionality, respectively (Scheme 28) ${ }^{[37]}$ Activation of the sulfoxides with $\mathrm{Tf}_{2} \mathrm{O}$ in the presence of 2,6-lutidine resulted in moderate levels of chirality transfer from sulfur to carbon and formation of spirocyclic oxindoles in moderate to good yields. The effect of the temperature and
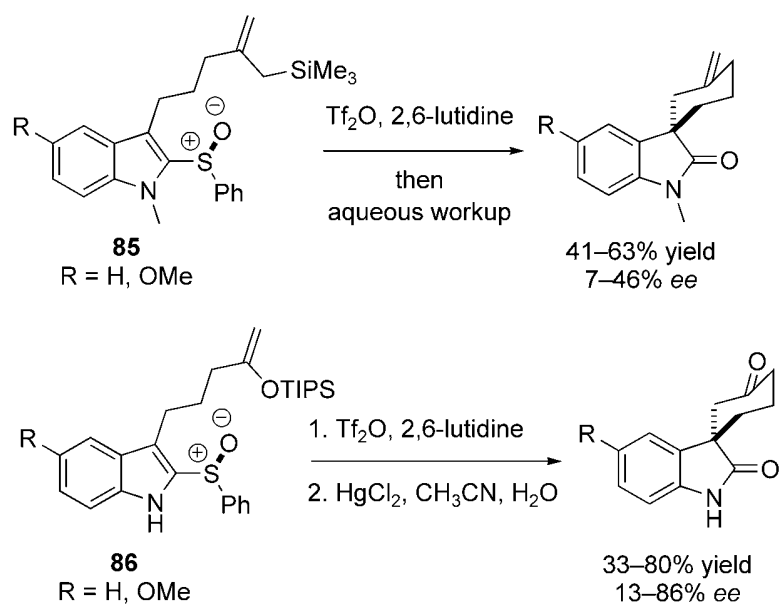

Scheme 28. Formation of enantioenriched spirooxindoles. TIPS $=$ triisopropylsilyl. the reaction solvent on the yield and enantiomeric excess of the product was evaluated: reaction in $\mathrm{MeCN}$ at $-40{ }^{\circ} \mathrm{C}$ gave the best results for allylsilane $\mathbf{8 5}$, whereas reaction in $\mathrm{Et}_{2} \mathrm{O}$ at $-110^{\circ} \mathrm{C}$ was found to be optimal for silyl enol ether $\mathbf{8 6}$. These reactions were proposed to proceed either through an $\mathrm{S}_{\mathrm{N}} 2^{\prime}$ like additive Pummerer sequence or through a tight ion pair resulting from an $\mathrm{S}_{\mathrm{N}} 1$-like vinylogous Pummerer reaction.

García Ruano, Padwa, and co-workers have reported a highly stereoselective rearrangement of ortho-sulfinyl alkyl benzenes $\mathbf{8 7}$ that is thought to involve a conjugated thionium ion intermediate $\mathbf{8 8}$ as an intimate ion pair with its counterion (Scheme 29). ${ }^{[38]}$ The rearrangement is triggered by lithiation

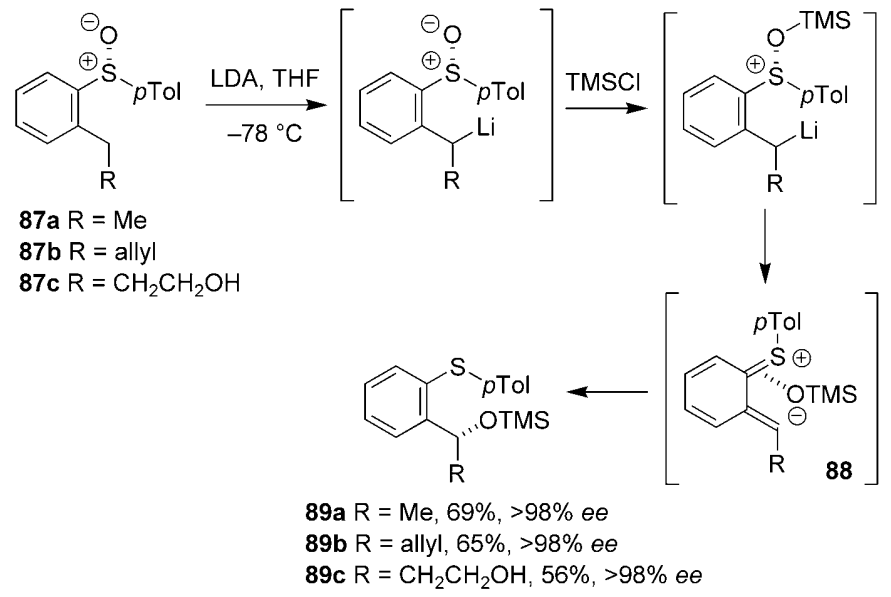

Scheme 29. Pummerer-type rearrangement of sulfinyl benzenes.

at the benzylic position with LDA and activation of the sulfoxide oxygen with TMSCl. A vinylogous Pummerer rearrangement is then thought to take place with transfer of stereochemical information occurring as a result of the nature of the tight ion pair. The stereoselective rearrangement provides a useful method for the synthesis of enantiomerically enriched benzylic alcohols $\mathbf{8 9}$ and a further example of the transfer of chirality from sulfur to carbon in Pummerer-type reactions (Scheme 29).

Nagao et al. have reported highly stereoselective asymmetric Pummerer reactions that exploit both inter- and intramolecular nonbonded S-O interactions. ${ }^{[39]}$ Although this type of interaction has been observed in X-ray crystal structures, analogous intermolecular nonbonded interactions are much more difficult to detect. Nagao and co-workers used cold-spray ionization mass spectrometry (CSI-MS) to detect molecular ions corresponding to complexes of sulfoxides with amides such as $\mathrm{N}, \mathrm{N}$-dimethylacetamide (DMA) and $\mathrm{N}$ methyl-2-pyrrolidinone (NMP). A combination of inter- and intramolecular nonbonded S-O interactions was then exploited in the asymmetric Pummerer reaction of enantiomerically pure sulfoxides such as $\mathbf{9 0 a}$ a,b to give acetoxysulfides 91 a,b in high enantiomeric excess (Scheme 30). The use of NMP or DMA as solvent was crucial for high chirality transfer as was the presence of the $\beta$-carbonyl group. The reaction is thought to proceed by formation of the NMP-TMSOTf complex 92 (detected by ${ }^{1} \mathrm{H}$ NMR spectroscopy and shown to be an acetylation catalyst when used with $\mathrm{Ac}_{2} \mathrm{O}$ ), which mediates the acetylation of sulfoxides $\mathbf{9 0}$ (shown with inter- 


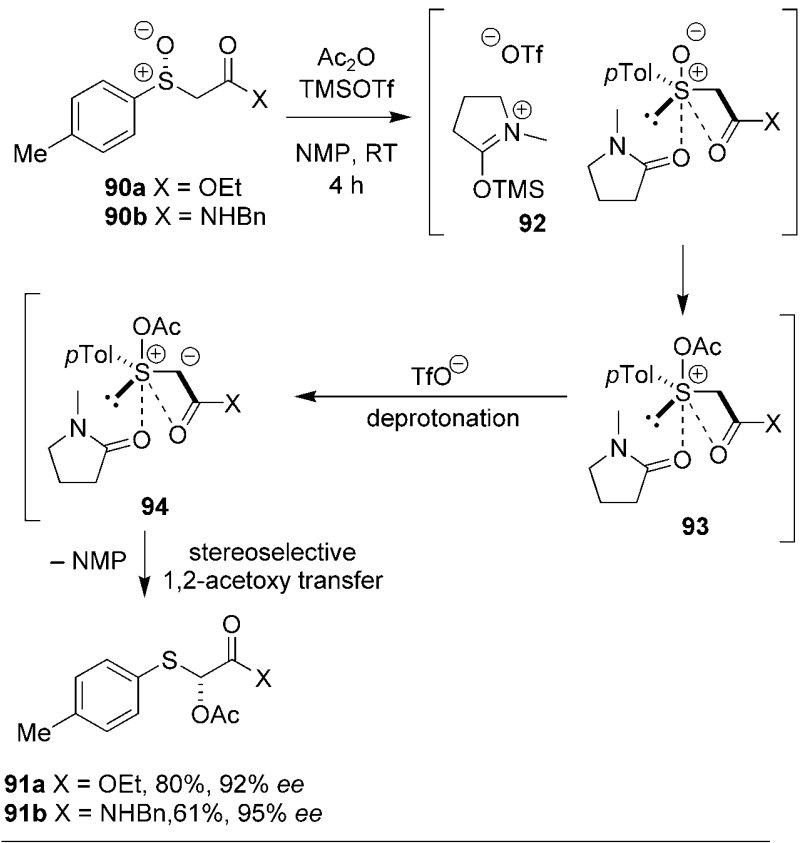

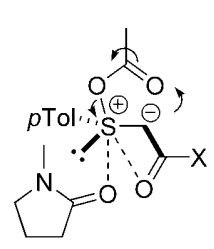

"cyclic" mode

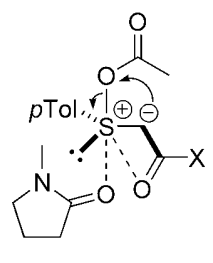

"sliding" mode

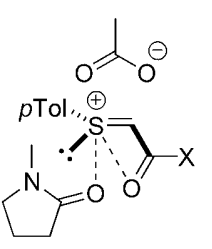

intimate
Scheme 30. Asymmetric Pummerer reactions devised by the Nagao group exploiting inter- and intramolecular nonbonded S-O interactions.

and intramolecular nonbonded S-O interactions). Deprotonation of sulfurane-type intermediates $\mathbf{9 3}$ then generates ylides 94 that undergo stereoselective 1,2-acetoxy transfer. 1,2-Acetoxy transfer may occur by "cyclic" or "sliding" modes ${ }^{[40]}$ or via an intimate ion pair ${ }^{[41]}$ (Scheme 30 ).

\section{The Pummerer Reaction in Natural Product Synthesis}

\subsection{A Synthesis of Monomorine}

Kuhakarn and co-workers have used a Pummerer-type cyclization to prepare common intermediate 97 in an approach to several indolizidine alkaloids. ${ }^{[42]}$ The cyclization of sulfoxide 95 was triggered by activation using Kita's Osilylated ketene acetal 96. The use of more conventional activating agents, such as TFAA or TMSOTf, to initiate the Pummerer process was unsuccessful (Scheme 31).

\subsection{Kita's Approach to ( \pm )- $\gamma$-Rubromycin}

Kita et al. employed two key aromatic Pummerer reactions in their total synthesis of $( \pm)-\gamma$-rubromycin $(\mathbf{1 0 4}),{ }^{[43]}$ an antibiotic and inhibitor of human immunodeficiency virus-1 reverse transcriptase and human telomerase (Scheme 32).

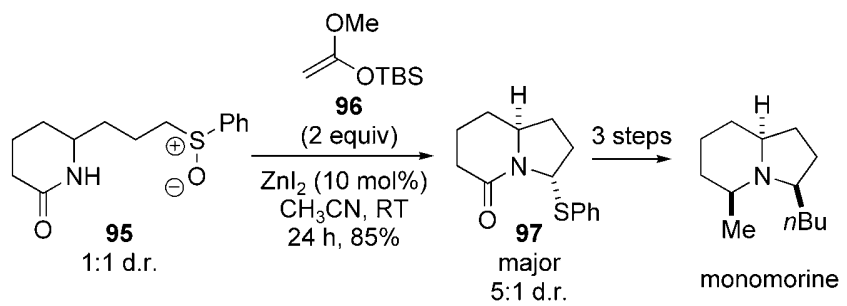

Scheme 31. A Pummerer cyclization in the synthesis of monomorine.<smiles>C=C1CCc2cc(CC(=O)OC)c(C(=O)OC)c(OC)c2O1</smiles><smiles>COc1cccc(CCC(=O)Oc2c(CC3=[O+]Cc4cc(CC(C)=O)c(C(C)=O)c(OC)c4O3)c(O)c3c(OC)cc(OC)cc3c2OC)c1</smiles><smiles>COCc1cc2c(c(OC)c1C(C)=O)OC1(CC2)Cc2c(c(OC)c(Sc3ccccc3)c3cc(OC)cc(OC)c23)O1</smiles>
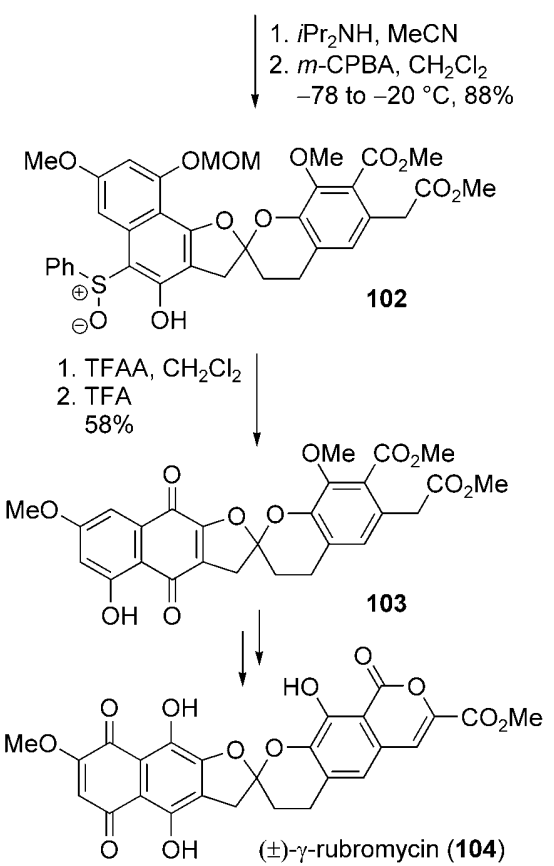

Scheme 32. Synthesis of $\gamma$-rubromycin by the Kita group. MOM=methoxymethyl, TFA $=$ trifluoroacetic acid. 
$\gamma$-Rubromycin features a central spiroketal motif which is important for its biological activity. In the first Pummerer reaction, activation of the sulfoxide $\mathbf{9 8}$ and 1,4-attack by enol ether $\mathbf{9 9}$ produced an oxonium ion $\mathbf{1 0 0}$, which cyclized to give spiroketal 101. After deprotection and oxidation to give sulfoxide 102, a second Pummerer step to remove the sulfanyl group and then acid-mediated ketal rearrangement gave $\mathbf{1 0 3}$, which was converted to $( \pm)-\gamma$-rubromycin in seven steps (Scheme 32).

\subsection{The CDE-Ring System of Erinacin E}

Kobayashi et al. used a Pummerer reaction in their approach to the CDE-ring system $\mathbf{1 0 9}$ of erinacin E (110), ${ }^{[4]}$ a potent stimulator of nerve growth factor synthesis (Scheme 33). The desired intermediate $\mathbf{1 0 7}$ was not formed by direct activation of the sulfide 105 with NCS or by treatment of the corresponding sulfoxide 106 with TFAA as a result of competing alcohol acylation. However, activation of the sulfoxide $\mathbf{1 0 6}$ using a bulky silyl chloride allowed isolation of the desired product $\mathbf{1 0 7}$ in good yield. Byproduct ketone
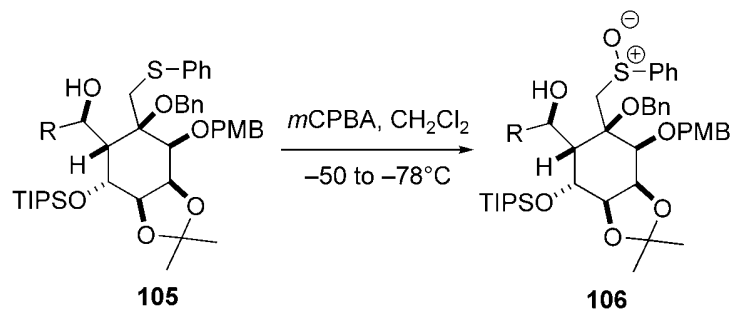

106

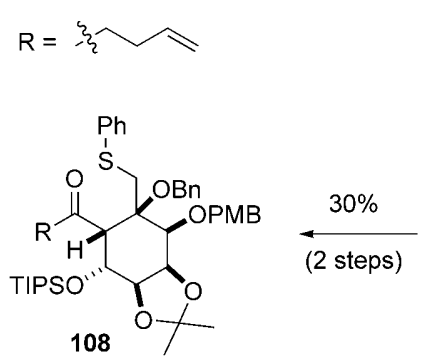

TBDPSCl
imidazole
DMF, $80^{\circ} \mathrm{C}$
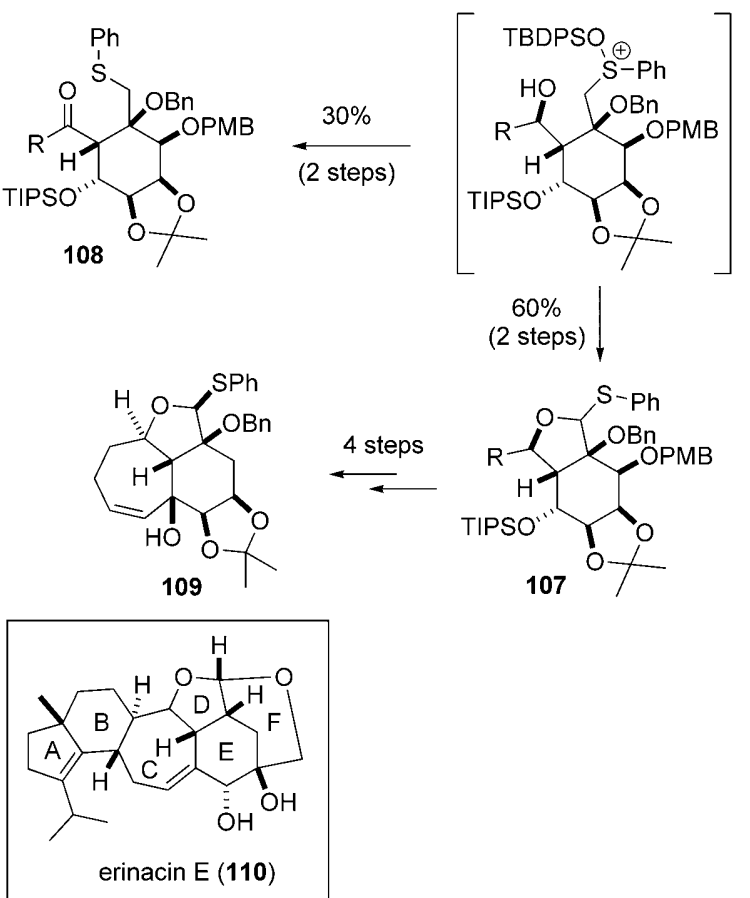

Scheme 33. The Kobayashi group's approach to the core of erinacin E.
108 was also isolated, presumably as a result of an interrupted Pummerer side reaction, followed by base-facilitated elimination (Scheme 33).

\subsection{Feldman's Synthesis of the Phakellin Alkaloids}

Feldman et al. have exploited extended Pummerer reactions in syntheses of three natural products, dibromophakellin (112), dibromophakellstatin (113), and dibromoagelaspongin (114), from intermediate 111 (Figure 1). ${ }^{[45-48]}$

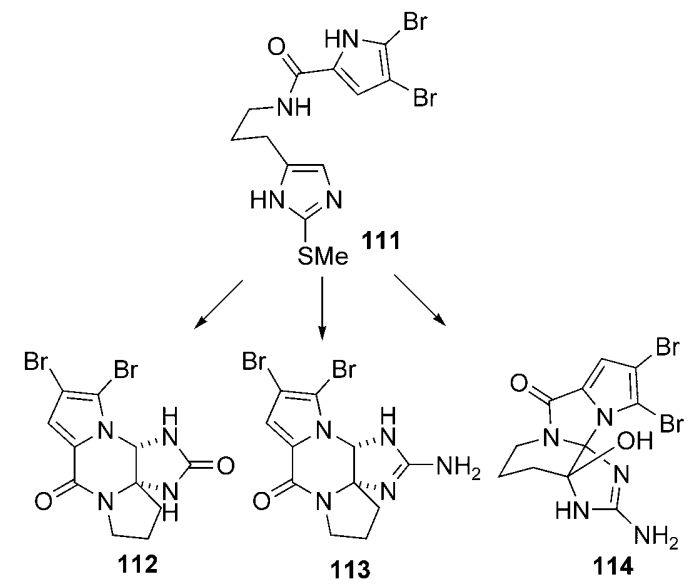

Figure 1. The natural products dibromophakellin (112), dibromophakellstatin (113), and dibromoagelaspongin (114).
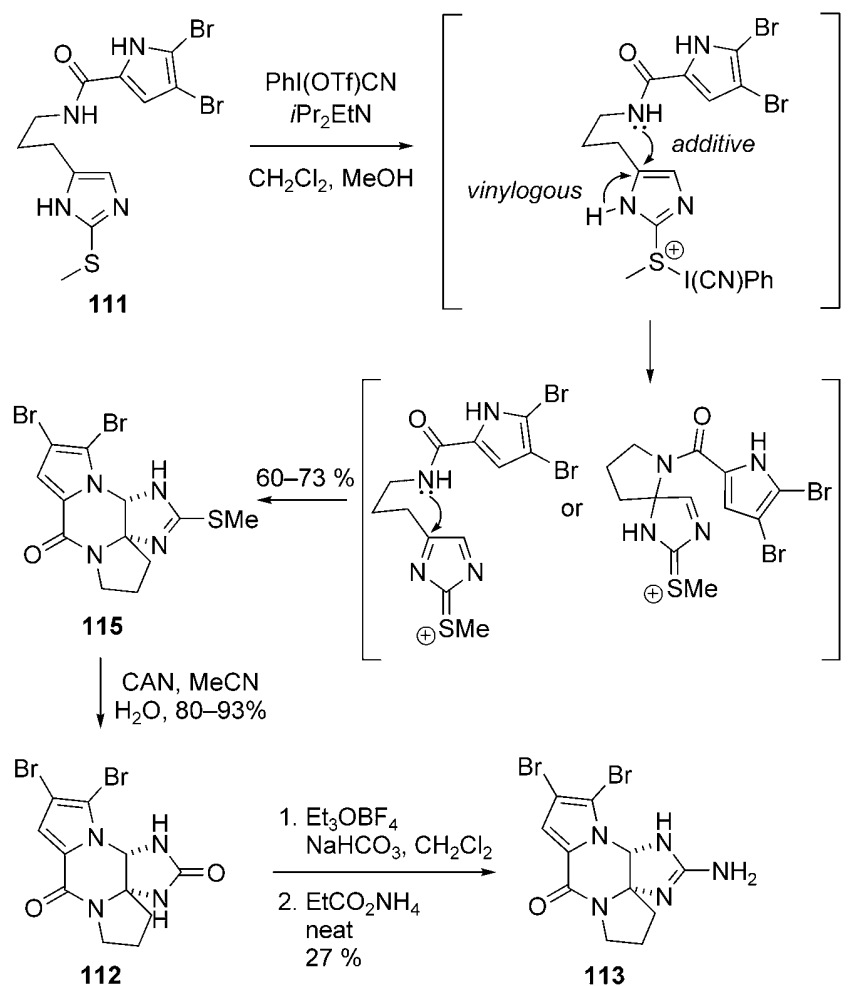

Scheme 34. Synthesis of dibromophakellstatin and dibromophakellin by the Feldman group. 
On activation with Stang's reagent, 111 underwent a cascade reaction to give tetracycle $\mathbf{1 1 5}$, which was converted to dibromophakellstatin (112) in one step in a CAN-initiated Pummerer reaction (Scheme 34). Compound 112 was then converted to dibromophakellin (113) in a further two steps. The exact reaction mechanism of the cyclization cascade has not been determined, but an additive or vinylogous pathway is plausible. Both pathways involve attack of the amide nitrogen onto the imidazole ring, followed by attack of the pyrrole nitrogen (Scheme 34) ${ }^{[45]}$

Two sequential Pummerer reactions were used in the Feldman group's synthesis of dibromoagelaspongin (Scheme 35). Sulfoxide 116 was activated under standard Pummerer conditions and underwent cyclization to give 119; the sulfamide protecting group on the imidazole ring gave rise to the altered regioselectivity compared to that in the dibromophakellin synthesis. The reaction may occur by either a vinylogous mechanism (formation of dication 117 and attack of the amide to give a five- or six-membered ring) or an additive mechanism (attack of the amide nitrogen to give $\mathbf{1 1 8}$ then a 1,2-shift). Following removal of the SEM protecting
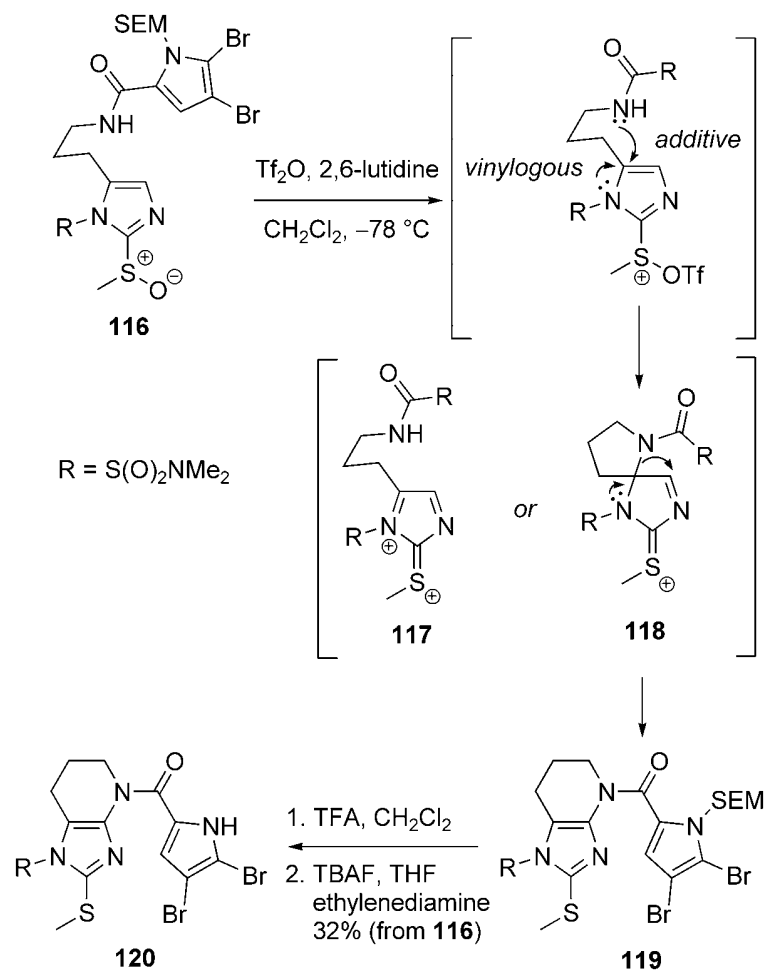

$\downarrow \begin{gathered}\mathrm{NCS}, \mathrm{CH}_{2} \mathrm{Cl}_{2} \\ 92 \%\end{gathered}$

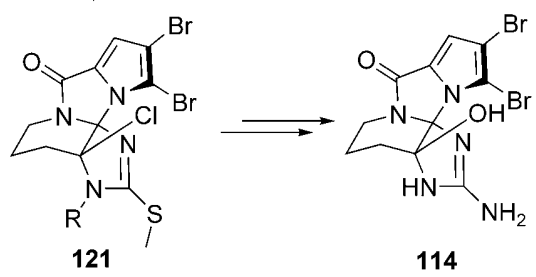

Scheme 35. Feldman's synthesis of dibromoagelaspongin using two extended Pummerer reactions. SEM $=$ [2-(trimethylsilyl)ethoxy]methyl, $\mathrm{TBAF}=$ tetrabutylammonium fluoride, $\mathrm{NCS}=\mathrm{N}$-chlorosuccinimide. group, exposure of $\mathbf{1 2 0}$ to NCS gave rise to tetracycle $\mathbf{1 2 1}$ in excellent yield. Despite extensive experiments to probe the mechanism, it is still unclear how this reaction operates, although initial electrophilic chlorination of sulfur is thought to be likely. Intermediate $\mathbf{1 2 1}$ was then converted to dibromoagelaspongin (114) in five steps (Scheme 35). ${ }^{[46-48]}$

\section{Summary and Outlook}

Pummerer and thionium chemistry has been applied successfully to the synthesis of a wide range of synthetically and biologically useful compounds and natural products; key advances include novel methods of thionium formation, use of thionium chemistry to trigger cyclization cascades, and the further development of asymmetric Pummerer reactions. The examples discussed in this Minireview illustrate the breadth and significance of recent progress, which will form the foundation for exciting future advances in the field.

Received: January 28, 2010

Published online: June 25, 2010

[1] a) R. Pummerer, Ber. Dtsch. Chem. Ges. 1909, 42, 228; b) R. Pummerer, Ber. Dtsch. Chem. Ges. 1910, 43, 1401

[2] S. K. Bur, A. Padwa, Chem. Rev. 2004, 104, 2401.

[3] K. S. Feldman, Tetrahedron 2006, 62, 5003.

[4] S. Akai, Y. Kita, Top. Curr. Chem. 2007, 274, 35.

[5] B. Laleu, P. Mobian, C. Herse, B. W. Laursen, G. Hopfgartner, G. Bernardinelli, J. Lacour, Angew. Chem. 2005, 117, 1913; Angew. Chem. Int. Ed. 2005, 44, 1879.

[6] B. Laleu, M. S. Machado, J. Lacour, Chem. Commun. 2006, 2786.

[7] K. S. Feldman, D. B. Vidulova, A. G. Karatjas, J. Org. Chem. 2005, 70, 6429.

[8] K. S. Feldman, A. Y. Nuriye, Tetrahedron Lett. 2009, 50, 1914.

[9] S. Yoshida, H. Yorimitsu, K. Oshima, Chem. Lett. 2008, 37, 786.

[10] S. Yoshida, H. Yorimitsu, K. Oshima, Org. Lett. 2009, 11, 2185.

[11] J. Liu, M. Wang, B. Li, Q. Liu, Y. Zhao, J. Org. Chem. 2007, 72, 4401.

[12] T. Miyagawa, T. Satoh, Tetrahedron Lett. 2007, 48, 4849.

[13] G. Xu, K. Chen, H. Zhou, Synthesis 2009, 3565.

[14] A. Arnone, P. Bravo, L. Bruche, M. Crucianelli, L. Vichi, M. Zanda, Tetrahedron Lett. 1995, 36, 7301.

[15] R. Sánchez-Obregón, F. Salgado, B. Ortiz, E. Diaz, F. Yuste, F. Walls, J. L. García Ruano, Tetrahedron 2007, 63, 10521.

[16] M. E. Eggers, P. V. Jog, D. K. Bates, Tetrahedron 2007, 63, 12185.

[17] I. A. O’Neil, K. M. Hamilton, Synlett 1992, 791.

[18] Y. Yoshimura, K. Kitano, H. Satoh, M. Watanabe, S. Miura, S. Sakata, T. Sasaki, A. Matsuda, J. Org. Chem. 1996, 61, 822.

[19] K. Haraguchi, H. Matsui, S. Takami, H. Tanaka, J. Org. Chem. 2009, 74, 2616.

[20] Y. Yoshimura, Y. Yamazaki, M. Kawahata, K. Yamaguchi, H. Takahata, Tetrahedron Lett. 2007, 48, 4519.

[21] Y. Yoshimura, Y. Yamazaki, Y. Saito, H. Takahata, Tetrahedron 2009, 65, 9091.

[22] M. Denancé, R. Legay, A.-C. Gaumont, M. Gulea, Tetrahedron Lett. 2008, 49, 4329.

[23] P. Dande, T. P. Prakash, N. Sioufi, H. Gaus, R. Jarres, A. Berdeja, E. E. Swayze, R. H. Griffey, B. Bhat, J. Med. Chem. 2006, 49, 1624.

[24] L. A. Paquette, S. Dong, J. Org. Chem. 2005, 70, 5655.

[25] H. Choo, X. Chen, V. Yadav, J. Wang, R. F. Schinazi, C. K. Chu, J. Med. Chem. 2006, 49, 1635. 
[26] K. Jayakanthan, B. D. Johnston, B. M. Pinto, Carbohydr. Res. 2008, 343, 1790.

[27] L. A. McAllister, R. A. McCormick, S. Brand, D. J. Procter, Angew. Chem. 2005, 117, 456; Angew. Chem. Int. Ed. 2005, 44, 452.

[28] L. A. McAllister, R. A. McCormick, K. M. James, S. Brand, N. Willetts, D. J. Procter, Chem. Eur. J. 2007, 13, 1032.

[29] a) For a review of sulfur and selenium linkers in phase tagassisted synthesis, see: L. A. McAllister, R. A. McCormick, D. J. Procter, Tetrahedron 2005, 61, 11527; b) For additional examples of the use of this linker system, see: K. L. Turner, T. M. Baker, S. Islam, D. J. Procter, M. Stefaniak, Org. Lett. 2006, 8, 329; c) L. A McAllister, K. L. Turner, S. Brand, M. Stefaniak, D. J. Procter, J. Org. Chem. 2006, 71, 6497.

[30] M. Miller, W. Tsang, A. Merritt, D. J. Procter, Chem. Commun. 2007, 498.

[31] a) M. Miller, J. C. Vogel, W. Tsang, A. Merrit, D. J. Procter, Org. Biomol. Chem. 2009, 7, 589; b) K. M. James, N. Willetts, D. J. Procter, Org. Lett. 2008, 10, 1203.

[32] C. Ovens, N. G. Martin, D. J. Procter, Org. Lett. 2008, 10, 1441.

[33] C. Ovens, J. C. Vogel, N. G. Martin, D. J. Procter, Chem. Commun. 2009, 3101.

[34] A. Seifert, R. Mahrwald, Tetrahedron Lett. 2009, 50, 6466.

[35] R. A. McCormick, K. M. James, N. Willetts, D. J. Procter, QSAR Comb. Sci. 2006, 25, 709. See also ref. [28].
[36] Z. Li, H. Li, X. Guo, L. Cao, R. Yu, H. Li, S. Pan, Org. Lett. 2008, $10,803$.

[37] K. S. Feldman, A. G. Karatjas, Org. Lett. 2006, 8, 4137.

[38] J. L. García Ruano, J. Alemán, M. T. Aranda, M. J. Arévalo, A. Padwa, Org. Lett. 2005, 7, 19.

[39] Y. Nagao, S. Miyamoto, M. Miyamoto, H. Takeshige, K. Hayashi, S. Sano, M. Shiro, K. Yamaguchi, Y. Sei, J. Am. Chem. Soc. 2006, 128,9722

[40] T. Numata, O. Itoh, T. Yoshimura, S. Oae, Bull. Chem. Soc. Jpn. $1983,56,257$.

[41] Y. Kita, N. Shibata, Synlett 1996, 289.

[42] C. Kuhakarn, P. Seehasombat, T. Jaipetch, M. Pohmakotr, V. Reutrakul, Tetrahedron 2008, 64, 1663.

[43] S. Akai, K. Kakiguchi, Y. Nakamura, I. Kuriwaki, T. Dohi, S. Harada, O. Kubo, N. Morita, Y. Kita, Angew. Chem. 2007, 119, 7602; Angew. Chem. Int. Ed. 2007, 46, 7458.

[44] S. Kobayashi, A. Ishii, M. Toyota, Synlett 2008, 1086.

[45] K. S. Feldman, A. P. Skoumbourdis, M. D. Fodor, J. Org. Chem. 2007, 72, 8076.

[46] K. S. Feldman, M. D. Fodor, J. Am. Chem. Soc. 2008, 130, 14964.

[47] K. S. Feldman, M. D. Fodor, J. Org. Chem. 2009, 74, 3449.

[48] K. S. Feldman, M. D. Fodor, A. P. Skoumbourdis, Synthesis 2009, 3162. 